\title{
TRANSTORNO DO DÉFICIT DE ATENÇÃO E HIPERATIVIDADE (TDAH): NEURO PSICOPEDAGOGIA COMO UMA ALIADA PARA MENINAS NA EDUCAÇÃO INFANTIL
}

\author{
Daniela dos Santos Ferreira Oliveira ${ }^{1}$ \\ Ana Paula Rodrigues ${ }^{2}$
}

RESUMO: Crianças com Transtorno de Déficit de Atenção e Hiperatividade (TDAH) geralmente apresentam problemas nas interações sociais. As funções executivas são responsáveis pelo comportamento e estão relacionadas ao repertório da cognição social. A cognição social está associada às capacidades de identificar, manipular e regular o comportamento a partir do processamento de pistas sociais percebidas e, são vistas como um fator de proteção para o indivíduo.

Palavras-chaves: Educação infantil. Neuro psicopedagogia. TDAH em meninas.

ABSTRACT: Children with Attention Deficit Hyperactivity Disorder (ADHD) often have problems in social interactions. Executive functions are responsible for behavior and are related to the repertoire of social cognition. Social cognition is associated with the ability to identify, manipulate and regulate behavior from the processing of perceived social cues and are seen as a protective factor for the individual.

Keywords: Early childhood education. Neuropsychopedagogy. ADHD in girls.

\section{INTRODUÇÃO}

O presente artigo tem como foco o transtorno do déficit de atenção e hiperatividade: Neuro psicopedagogia como uma aliada para meninas na educação infantil, tendo como objetivo geral identificar as principais contribuições da neuro psicopedagogia para meninas no ensino infantil.

Em seu desenvolvimento caracteriza-se em uma pesquisa de abordagem qualitativa, tendo como objetivo de estudo exploratório onde tem o intuito de explorar a revisão

\footnotetext{
${ }^{\mathrm{I}}$ Especialista em neuro psicopedagogia

${ }^{2}$ DSc. em educação
} 
bibliográfica sobre o tema transtorno do déficit de atenção, em busca de descrever a neuro psicopedagogia como uma aliada a meninas na educação infantil.

Através da análise bibliográfica de forma exploratória de investigar teoricamente e descrever sobre o mesmo constatou-se que a escola precisa estar preparada para enfrentar os desafios e necessidades.

Mas, Quais as principais contribuições da neuro psicopedagogia para meninas na educação infantil com transtorno do déficit de atenção? $O$ processo de aprendizagem do aluno é primordial para que ele possa se desenvolver a nível cognitivo e emocional, porém só é possível quando estabelece uma relação harmoniosa entre corpo e mente, e quando as funções neurofisiológicas, psíquicas e comportamentais estão funcionando intrinsecamente.

Quando esta relação não ocorre surgem os diversos problemas comprometendo a aprendizagem do aluno, o que é comum nos casos de alunos portadores de TDHA (Transtorno de déficit de Atenção).

Com o advento e desenvolvimento dos estudos das neurociências juntamente com a educação, hoje é possível compreender e buscar meios para encontrar respostas e sanar lacunas sobre temas ora antes não compreendidas sobre os transtornos de aprendizagem e como trabalhar com alunos portadores de TDHA.

Porém, é importante compreender o papel da neuro psicopedagogia no ambiente escolar. Assim, justifica-se que a neuro psicopedagogia tem se mostrado uma grande aliada ao tratamento do TDAH em meninas, pois ao entendermos como o cérebro da criança trabalha torna-se mais fácil o tratamento como também a convivência família e escolar.

Por tanto, encontrará no desenvolver da leitura do artigo em sua fundamentação teórica sobre o tema abordado terá três tópicos. $O$ primeiro tópico intitulado NEUROPSICOPEDAGODIA, falando resumidamente o que é a mesma.

O segundo tópico abordará a CONCEITUAÇÃO SOBRE TRANSTORNO DO DÉFICIT DE ATENÇÃO E HIPERATIVIDADE, onde aborda as características do tdah. E 
por fim, o terceiro tópico intitulado como FUNÇÕES EXECUTIVAS DA APRENDIZAGEM, retrata sobre as habilidades cognitivas.

\section{OBJETIVO GERAL}

Identificar as contribuições da neuro psicopedagogia nas meninas que apresentam transtorno de déficit de atenção e hiperatividade.

\section{OBJETIVO ESPECIFICO}

Descrever sobre a neuro psicopedagogia

Definir o transtorno do déficit de atenção e hiperatividade

Conceituar as funções executivas da aprendizagem

\section{DESENVOLVIMENTO 4.I NEURO PSICOPEDAGOGIA}

Basicamente, a Neuro psicopedagogia é uma ciência transdisciplinar, fundamentada 909 nos conhecimentos da neurociência aplicada para a educação, com dispositivos para troca de informações entre a Pedagogia e Psicologia Cognitiva que tem como objeto formal de estudo a relação entre o funcionamento do sistema nervoso e a aprendizagem humana numa perspectiva de reintegração pessoal, social e educacional, conforme aponta o art. ıo ${ }^{o}$ da resolução 03/2014, da SBNPp (Sociedade Brasileira de Neuro psicopedagogia).

\subsection{CONCEITUAÇÃO DO TRANSTORNO DE DÉFICIT DE ATENÇÃO HIPERATIVIDADE (TDAH)}

Para determinar um conceito acerca de um problema específico de ordem clínica, a identificação de eventuais anormalidades é o primeiro passo a ser dado pelo profissional imbuído de fazer esse estudo de caso.

No que se refere ao Transtorno de Déficit de Atenção e Hiperatividade - TDAH, sua conceituação clínica, além de classificar o problema em si, permitirá um entendimento 
preliminar acerca de suas resoluções e adequações para determinadas finalidades, visto que sua definição pode ser classificada como "um transtorno neurocomportamental, multifatorial, cuja característica principal é um padrão persistente de desatenção e ou hiperatividade/impulsividade, que frequentemente resulta em prejuízos emocionais, sociais e, sobretudo, funcionais (SILVA, 2009).

O TDAH é caracterizado pela falta de atenção de um indivíduo e a falta de compreensão nítida das propostas apresentadas em sala de aula pelos professores, sendo que essa falta de compreensão acarreta danos comprometedores, não apenas ao seu rendimento escolar, mas também nas suas percepções de um modo geral no cotidiano.

Afeta o desenvolvimento e a interação do indivíduo em todos os mementos da sua vida, de acordo com o DSMos (Manual de saúde mental), o TDAH é um Transtorno do desenvolvimento. Sua caracterização permitirá não apenas a família, mas primordialmente a gestão escolar, no sentido de delimitar projetos e iniciativas de intervenção que adequem as limitações e potenciais dos alunos, frente à construção do processo de ensino-aprendizagem, sobretudo, na ótica da educação inclusiva e socializadora.

\subsection{FUNÇÕES EXECUTIVAS DA APRENDIZAGEM}

O dicionário da International Neuropsychological Society define funções executivas como "as habilidades cognitivas necessárias para realizar comportamentos complexos dirigidos para determinado objetivo e a capacidade adaptativa as diversas demandas e mudanças ambientais" (Loring, 1999).

Tradicionalmente, referem-se às habilidades cognitivas envolvidas no planejamento, iniciação, seguimento e monitoramento de comportamentos complexos dirigidos a um fim.

$\mathrm{Na}$ avaliação neuropsicológica, a denominação FE é utilizada para designar uma ampla variedade de funções cognitivas que implicam: atenção, concentração, seletividade de estímulos, capacidade de abstração, planejamento, flexibilidade de controle mental, autocontrole e memória operacional (Green, 2000; Loring, 1999; Spreen \& Strauss, 1998). 
Inúmeros testes e baterias neuropsicológicas têm sido empregados para avaliar as $\mathrm{FE}$ (Green, 200o; Spreen \& Strauss, 1998). Déficits nas FE tem sido relacionada a alterações dos lobos frontais. Contudo, dúvidas metodológicas e conceituais sobre o q Pela importância que as funções executivas têm na otimização e no controle da prestação cognitiva e conativa, quer em situação de sobrevivência e de adaptação ao meio, quer de aprendizagem, de comportamento e de interação social, vejamos em particular alguns dos seus pontos mais relevantes para a educação e para o sucesso escolar.

As funções executivas coordenam e integram o espectro da tríade neuro funcional da aprendizagem, onde estão conectadas com as funções cognitivas e conativas que acabamos de abordar. O seu piloto, diretor executivo, líder ou maestro neuro funcional avançado é o córtex pré-frontal, região que ocupa no cérebro humano quase um terço do seu volume cortical.

Como posto de comando que é do cérebro, o córtex pré-frontal tem que manter excelentes linhas de comunicação com todas as outras áreas, sendo mesmo a sua região mais conectada, daí a sua função de coordenação e de integração das funções cognitivas e conativas na aprendizagem.

O córtex pré-frontal está intimamente conectado com o córtex associativo posterior, a mais elevada estrutura de integração perceptiva e de reconhecimento multissensorial (visual, auditivo e tátil-cinestésico), e obviamente conectado com o córtex pré (psico) motor, com os gânglios da base e com o cerebelo, todos envolvidos na planificação, controle e execução da motricidade

Ler e compreender, formular ideias e escrevê-las, apreender enunciados de problemas matemáticos e planificar uma série de procedimentos e operações para chegar à solução correta pode revelar a luta que muitas crianças e jovens travam na sala de aula.

A maioria das tarefas escolares exige, de fato, a coordenação e a integração coerente das múltiplas funções executivas, não é de estranhar, portanto, que muitas crianças e jovens com disfunções ou dificuldades executivas ou com funções executivas vulneráveis e afuniladas, apresentem problemas de sobrecarga de informação de produtividade, de eficácia e 
de precisão nos seus desempenhos escolares. As meninas e que apresentam sintomas de Hiperatividade e Impulsividade mais marcantes, expressa de forma diferente da dos meninos. São menos rebeldes, menos opositivas, e a Hiperatividade se expressa através da fala e da ação. Como a comorbidade com os Transtornos de Ansiedade e Depressão são os mais presentes, costumam ter uma instabilidade emocional importante, com constantes mudanças de humor.

As meninas com o tipo Predominantemente Desatento se mostram sonhadoras e tímidas. Elas se esforçam para não chamar atenção. Aparentam estar ouvindo enquanto suas mentes divagam. Podem parecer ansiosas na relação escola, esquecidas e desorganizadas com o dever de casa e atrasar a entrega de trabalhos. Costumam ter um ritmo lento e a sensação de sobrecarga. Algumas são ansiosas ou depressivas e vistas erradamente como menos inteligentes do que realmente são.

\section{CONSIDERAÇÕES FINAIS}

Este artigo define a importância de ampliar os estudos sobre a contribuição da neuro psicopedagogia com alunos portadores de TDHA, foi possível adquirir uma visão sobre a pesquisa e sua importância para a compreensão dos processos da aprendizagem, onde possibilitará um olhar mais reflexivo no que compete os conceitos relacionados a neuro psicopedagogia, que estuda a relação entre o cérebro e comportamento. Dessa forma, este estudo pode auxiliar na compreensão do caso em questão, a fim de possibilitar análises futura para propostas interventivas, em contribuição ao desempenho acadêmico e social.

\section{REFERÊNCIAS BIBLIOGRÁFICAS}

Green, J. (2000). Neuropsychological evaluation of the older adult: A clinician's guidebook. San Diego, CA: Academic Press 
Loring, D. (Ed.). (1999). INS Dictionary of neuropsychology. New York: Oxford University Press

SILVA, A. B. B. Mentes inquietas: TDH - desatenção, hiperatividade e impulsividade. Rio de Janeiro: Objetiva, 2009.

SOCIEDADE BRASILEIRA DE NEUROPSICOPEDAGOGIA (SBNPp). Conselho técnicoprofissional. Nota Técnica. № 02/2017.

SOCIEDADE BRASILEIRA DE NEUROPSICOPEDAGOGIA (SBNPp). Neuropsicopedagogo institucional e clínico. Comentários ao art. 29 do Código de Ética Técnico I9 Profissional (2015).

Spreen, O., \& Strauss, E. (1998). A compendium of neuropsychological tests. Administration, norms, and commentary. New York: Oxford University Press.

SITES:<file:///C:/Users/fabia/Downloads/ebookandreafinal.pdf〉 acesso em 26 de janeiro 202I.

<file:///C:/Users/fabia/Pictures/Pereira_CamiladeFatima_M.pdf\%2opara\%200\%2otcc\%2ofav eni\%2oneuropsicopedagogia.pdf $>$ acesso em 20 de janeiro 202I

<https://tdah.org.br/tdah-em-

mulheres/https://periodicos.ufpe.br/revistas/cadernoscap/article/viewFile/24128I/34025>aces so em is de janeiro 202I

〈http://pepsic.bvsalud.org/scielo.php?script=sci_arttext \&pid=So103-84862014000300002 acesso em ro de janeiro 202I 
〈https://www.redalyc.org/pdf/r88/18813652009.pdf > acesso em 7 de janeiro 202I

<https://meuartigo.brasilescola.uol.com.br/educacao/transtorno-de-deficit-de-atencao-ehiperatividade-aprendizado-atraves-da-neuropsicopedagogia.htm> acesso em 19 dezembro de 2020 $<$ https://www.scielo.br/scielo.php?pid=Soroz37722010000400o15\&script=sci_abstract\&tlng=eshttps://ri.ufs.br/bitstream/riufs/8949/8/Con tribuicao_da_neuropsicopedagogia_com_alunos_portador_de_tdha.pdf $>$ acesso em I5 de dezembro de 2020 